\title{
Enhanced Integration of Motion Information in Children With Autism
}

\author{
Catherine Manning, ${ }^{1,2}$ Marc S. Tibber, ${ }^{3}$ Tony Charman, ${ }^{4}$ Steven C. Dakin, ${ }^{3,5}$ and Elizabeth Pellicano ${ }^{1,6}$ \\ ${ }^{1}$ Centre for Research in Autism and Education, UCL Institute of Education, University College London, London WC1H 0NU, United Kingdom, ${ }^{2}$ Department \\ of Experimental Psychology, University of Oxford, Oxford OX1 3UD, United Kingdom, ${ }^{3}$ Institute of Ophthalmology, University College London, London \\ EC1V 9EL, United Kingdom, ${ }^{4}$ Institute of Psychiatry, Psychology \& Neuroscience, King's College London, London SE5 8AF, ${ }^{5}$ Department of Optometry and \\ Vision Science, University of Auckland, Auckland 1142, New Zealand, and ${ }^{6}$ School of Psychology, University of Western Australia, Perth 6009, Australia
}

To judge the overall direction of a shoal of fish or a crowd of people, observers must integrate motion signals across space and time. The limits on our ability to pool motion have largely been established using the motion coherence paradigm, in which observers report the direction of coherently moving dots amid randomly moving noise dots. Poor performance by autistic individuals on this task has widely been interpreted as evidence of disrupted integrative processes. Critically, however, motion coherence thresholds are not necessarily limited only by pooling. They could also be limited by imprecision in estimating the direction of individual elements or by difficulties segregating signal from noise. Here, 33 children with autism $6-13$ years of age and 33 age- and ability-matched typical children performed a more robust task reporting mean dot direction both in the presence and the absence of directional variability alongside a standard motion coherence task. Children with autism were just as sensitive to directional differences as typical children when all elements moved in the same direction (no variability). However, remarkably, children with autism were more sensitive to the average direction in the presence of directional variability, providing the first evidence of enhanced motion integration in autism. Despite this improved averaging ability, children with autism performed comparably to typical children in the motion coherence task, suggesting that their motion coherence thresholds may be limited by reduced segregation of signal from noise. Although potentially advantageous under some conditions, increased integration may lead to feelings of "sensory overload" in children with autism.

Key words: autism; developmental disorders; motion perception

\section{Introduction}

Visual motion processing is essential for navigating within a dynamic world and contributes to a range of basic visual functions, including scene segmentation, depth perception, and object identification. Atypicalities in motion processing could therefore have a profound impact on how an individual perceives and interacts with the world. A large literature suggests that motion processing is atypical in autism, a neurodevelopmental condition most well known for its effects on social communication. Reduced sensitivity to motion information in autism has been reported in tasks such as coherent

Received Oct. 21, 2014; revised Feb. 4, 2015; accepted Feb. 25, 2015

Author contributions: C.M., M.S.T., T.C., S.C.D., and E.P. designed research; C.M. performed research;C.M., M.S.T., and S.C.D. analyzed data; C.M., M.S.T., T.C., S.C.D., and E.P. wrote the paper

This work was supported by the Economic and Social Research Council (studentship to C.M.), the Medical Research Council (Grant MR/J013145/1 to E.P.), and the Wellcome Trust (Grant 088219 to S.C.D.). Research at CRAE (C.M., E.P) is supported by The Clothworkers' Foundation and Pears Foundation. We thank all the schools and families who participated in this research; R. McMillin and A. Rudnicka for help with testing; and D.H. Baker, R. Bedford, A. Remington, J.A. Solomon, and S.G. Solomon for useful discussions.

The authors declare no competing financial interests.

This article is freely available online through the J Neurosci Author Open Choice option.

Correspondence should be addressed to Catherine Manning, Department of Experimental Psychology, 9 South Parks Road, 0xford 0X1 3UD, UK. E-mail: catherine.manning@psy.ox.ac.uk.

DOI:10.1523/JNEUROSCI.4645-14.2015

Copyright $\odot 2015$ Manning et al.

This is an Open Access article distributed under the terms of the Creative Commons Attribution License Creative Commons Attribution 4.0 International, which permits unrestricted use, distribution and reproduction in any medium provided that the original work is properly attributed. motion (Milne et al., 2002; Pellicano et al., 2005) and biological motion perception (Blake et al., 2003; Annaz et al., 2010, 2012), whereas in other tasks, individuals with autism perform similarly to typical individuals (Bertone et al., 2003; Pellicano et al., 2005; Manning et al., 2013). Intriguingly, there are also some reports of increased sensitivity to motion information in autism (Chen et al., 2012; Foss-Feig et al., 2013).

A framework often applied to explain this complex pattern of performance is the distinction between local and global processing (Frith and Happé, 1994; Mottron et al., 2006). Local motion processing (e.g., detecting the direction of individual elements) relies on early visual areas such as V1 (Hubel and Wiesel, 1962). In contrast, global motion processing requires pooling information across space and time and depends on higher areas of the motion-processing hierarchy, such as MT/V5 that integrates input from motion-selective neurons in V1 (Newsome et al., 1985). Elevated thresholds in autistic individuals are often reported in tasks purportedly requiring extensive integration, such as the motion coherence task, in which participants report the direction of coherently moving dots among randomly moving dots (Newsome and Paré, 1988). However, elevated motion coherence thresholds do not necessarily arise from reduced integration (Dakin and Frith, 2005) but could also arise from imprecision in estimating the direction of individual dots (Barlow and Tripathy, 1997) or difficulties segregating signal from noise (Dakin et al., 2005; Tibber et al., 2014). Indeed, poor estimation of local direc- 

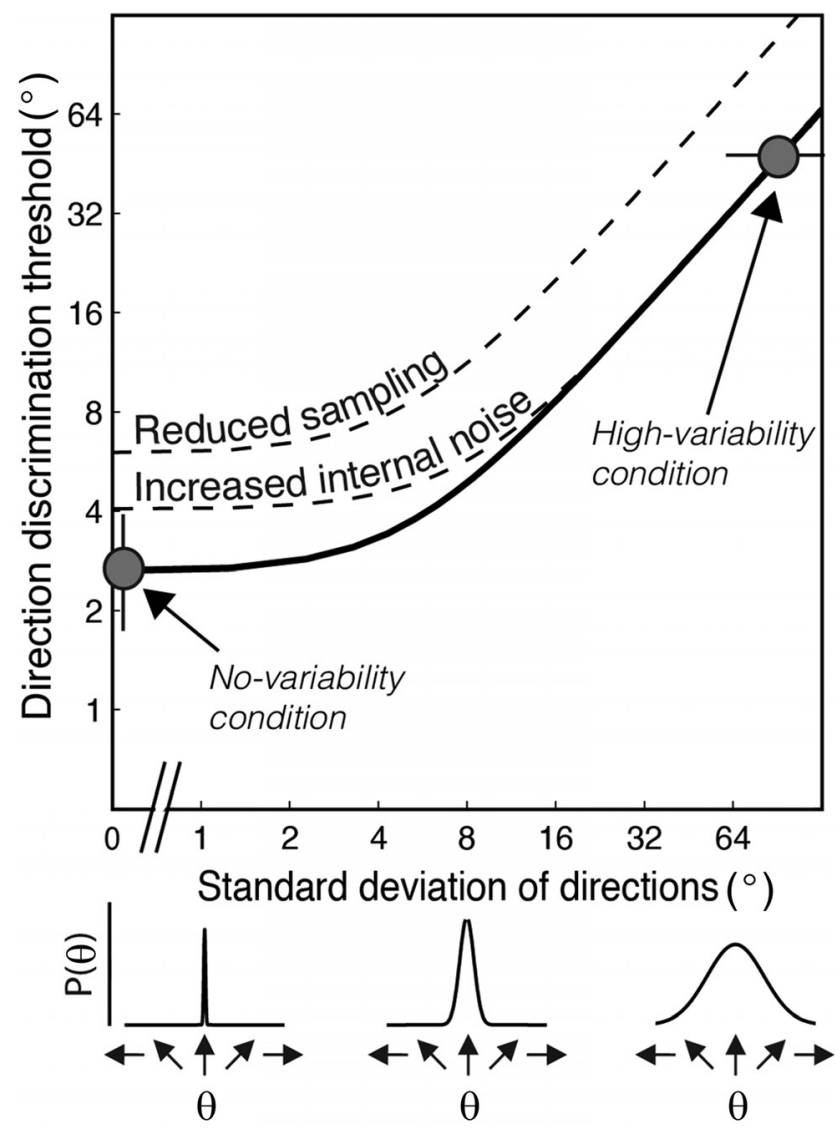

Figure 1. Equivalent noise analysis. The equivalent noise function relating direction discrimination thresholds to SD of dot directions (i.e., external noise; Dakin et al., 2005). From this function, two independent limits on direction integration performance can be derived: internal noise, which maps onto the precision with which individual motion directions are estimated, and sampling, which is the effective number of local motion directions that are globally pooled (or averaged). Direction discrimination thresholds are limited by external noise and internal noise in an additive manner. When small amounts of external noise are added to the stimulus, thresholds do not change. However, when the level of external noise exceeds the level of internal noise, thresholds increase. Participants with higher levels of internal noise will require more external noise to be added until thresholds increase (lower dotted line). Performance is also affected by how many samples are averaged to compute the mean direction. When fewer samples are averaged, the equivalent noise function is shifted vertically upward (upper dotted line). For each participant, an equivalent noise function was constrained using the basic direction threshold in the no-variability condition and the maximum level of variability that could be tolerated for discriminating a coarse $\left( \pm 45^{\circ}\right)$ signal in the high-variability condition (Manning et al., 2014; Tibber et al., 2014, 2015; shown as gray circles).

tions could be a consequence of increased internal noise in autism (Simmons et al., 2009; but see Davis and Plaisted-Grant, 2015 , for an account proposing reduced noise in autism).

Here, we used an informative direction integration task that required children to report the mean direction of dots both in the presence and absence of directional variability. Unlike in motion coherence tasks, this task does not require observers to segregate signal from noise because all dots are signal dots, with directions sampled from Gaussian distributions (Dakin et al., 2005). In addition, we modeled performance in the no-variability and highvariability conditions using an equivalent noise approach (Dakin et al., 2005; Manning et al., 2014; Fig. 1) in an attempt to quantify the extent to which local noise and/or global averaging contribute to direction integration in children with autism. For comparison with previous studies, participants also performed a standard motion coherence task. We hypothesized that children with autism would show elevated thresholds in both tasks and that this would be related to reduced averaging in conjunction with atypical levels of internal noise.

\section{Materials and Methods}

Participants. Participants included 33 children with autism (three females) between 6 and 13 years of age and 33 typically developing children ( 10 females) individually matched in age, verbal IQ, and nonverbal IQ, as measured by the Weschler Abbreviated Scales of Intelligence (Wechsler, 1999, 2011; see Table 1 for scores). All children with autism had received an independent clinical diagnosis of autism or Asperger syndrome according to ICD-10 criteria (World Health Organization, 1993). Parents completed the Social Communication Questionnaire (SCQ)-Lifetime Version (Rutter et al., 2003) and children with autism were administered the Autism Diagnostic Observation Schedule (ADOS) by a researcher trained for research-reliability purposes (ADOS-G or ADOS-2; Lord et al., 1999, 2012) using the revised algorithm (Gotham et al., 2007, 2008). All participants in the autism group met criteria for an autism spectrum disorder on one or both of these measures (Manning et al., 2013). The majority of children with autism met criteria on both measures, with only two children with autism scoring below the cutoff for autism on the SCQ $(<15)$ and seven scoring below the cutoff on the ADOS. All typical children scored below the cutoff for autism on the SCQ. All children had normal or corrected-to-normal visual acuity, defined as a binocular acuity of 6/9 or better for children aged 8 years and under [because acuity is still maturing at this age (Bradley and Freeman, 1982; Adams and Courage, 2002)] and $6 / 6$ or better for older children.

The procedure was performed in agreement with the principles of the Declaration of Helsinki and was approved by the Institute's Faculty Research Ethics Committee. Parents gave their informed consent and children verbally assented. The experimental tasks were presented in two separate sessions of $\sim 25$ min including breaks, with each session comprising of one direction integration task and one motion coherence task. The order of presentation of conditions was counterbalanced between participants. During the experimental tasks, participants were seated in a dimly illuminated room with a chin rest at a distance of $51 \mathrm{~cm}$ from the monitor. Participants were instructed to maintain central fixation throughout stimulus presentation and the experimenter monitored this throughout, providing regular reminders.

Stimuli. Stimuli were presented on a Dell Precision M4600 laptop $(1366 \times 768$ pixels; $60 \mathrm{~Hz})$ using MATLAB and elements of the Psychophysics Toolbox (Brainard, 1997; Pelli, 1997; Kleiner et al., 2007). A yellow-bordered circular aperture $\left(15^{\circ}\right.$ diameter $)$ and an anchor-shaped fixation point $\left(0.57^{\circ} \times 0.57^{\circ}\right)$ were presented centrally on a gray screen (Fig. 2A). Two smaller yellow-bordered circular apertures (diameter $6.12^{\circ}$ ) were presented to the left and right of the aperture and contained red and green images, respectively, that served as reference points. Stimuli were unlimited lifetime random dot patterns moving for $400 \mathrm{~ms}$ within the central aperture. Each stimulus consisted of 100 white dots (diameter $0.44^{\circ}$ ). Dot positions were updated every 3 frames with displacements of $0.075^{\circ}$ in the slow $\left(1.5^{\circ} / \mathrm{s}\right)$ and $0.3^{\circ}$ in the fast $\left(6^{\circ} / \mathrm{s}\right)$ condition.

Procedure. Children completed a direction integration task with two interleaved conditions (no-variability, high-variability) and a motion coherence task in slow $\left(1.5^{\circ} / \mathrm{s}\right)$ and fast $(6 \% \mathrm{~s})$ speed conditions (because motion processing atypicalities in autism may depend on stimulus speed; Manning et al., 2013). In the direction integration task, dot directions were randomly sampled from a wrapped normal distribution with a specified mean and SD. In the no-variability condition, the SD of dot directions was $0^{\circ}$ and the mean direction of dots was varied from vertical to find the finest direction discrimination possible in the absence of stimulus variability. In the high-variability condition, the mean direction of dots was fixed at $\pm 45^{\circ}$ from vertical and the SD of dot directions was varied to find the maximum level of variability that could be tolerated while successfully identifying the signal direction. In the motion coherence task, a proportion of dots moved in a coherent direction $\left( \pm 90^{\circ}\right.$ from vertical) while the remaining dots moved in random directions.

The tasks were presented within the context of child-friendly games in which they had to determine whether the shoal of "fish" swam to the red (left) or green (right) reef or rocks (Manning et al., 2014). To aid moti- 
Table 1. Participant characteristics

\begin{tabular}{|c|c|c|c|}
\hline Measure & Children with autism $(n=33)^{a}$ & Typically developing children $(n=33)^{a}$ & Results of independent $t$ test \\
\hline Age (y) & 10.13 (2.03) 5.95-12.97 & 10.13 (1.77) $6.00-13.09$ & $t_{(64)}=0.40, p=0.69$ \\
\hline Verbal IQ & $98.39(9.92) 80-120$ & $102.00(10.48) 76-118$ & $t_{(64)}=1.44, p=0.16$ \\
\hline Performance IQ & $105.21(15.35) 72-137$ & 104.33 (11.99) 84-131 & $t_{(64)}=0.26, p=0.80$ \\
\hline Full-scale IQ & $102.03(12.15) 75-127$ & 103.58 (10.10) 85-124 & $t_{(64)}=0.56, p=0.58$ \\
\hline SCQ score & $24.89(7.70) 5-38$ & $4.70(4.40) 0-14$ & $t_{(43.24)}=11.99, p<0.01$ \\
\hline ADOS overall total & $11.03(5.75) 2-23$ & & \\
\hline
\end{tabular}

${ }^{a}$ Data are presented as $\mathrm{M}(\mathrm{SD})$ range.

${ }^{b} \mathrm{SCO}$, Social Communication Questionnaire (Rutter et al., 2003).

‘ADOS, Autism Diagnostic Observation Schedule (Lord et al., 1999, 2012).
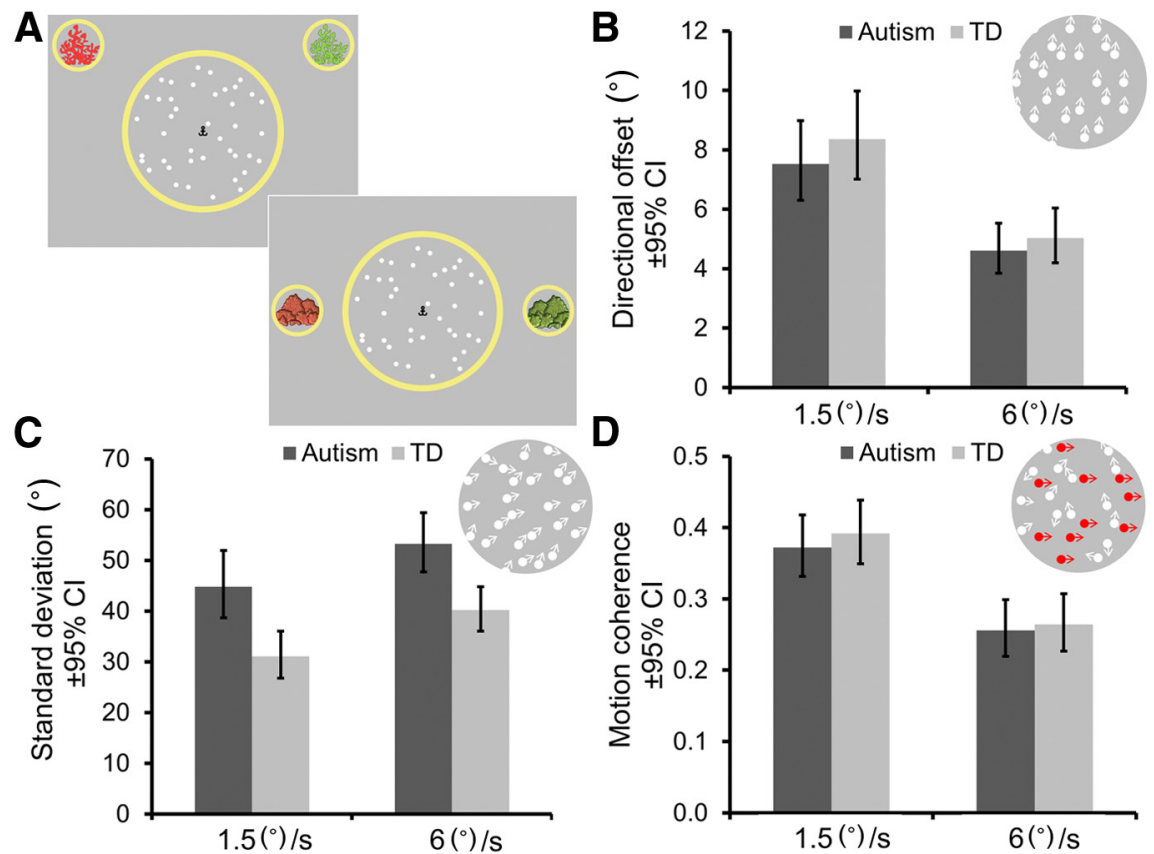

Figure 2. Schematic representation of stimuli and results for children with autism and typically developing (TD) children. $\boldsymbol{A}$, Schematic representation of display presented in the direction integration (top) and motion coherence (bottom) tasks. The anchorshaped fixation point, central yellow aperture and red (left) and green (right) "reefs" or "rocks" remained on the screen throughout the trial. $\boldsymbol{B}$, Mean direction discrimination thresholds [ $\pm 95 \%$ confidence interval $(\mathrm{Cl})]$ in the absence of stimulus variability (no-variability condition) for children with autism (dark bars) and typical children (TD; light bars) in slow $\left(1.5^{\circ} / \mathrm{s}\right)$ and fast $\left(6^{\circ} / \mathrm{s}\right)$ conditions. Inset is a representation of an example stimulus where dot directions are drawn from a distribution with $\mathrm{M}=+8^{\circ}$ and $\mathrm{SD}=0^{\circ}$. Arrows are presented for illustrative purposes only. $\mathrm{C}$, The mean level of variability $( \pm 95 \% \mathrm{Cl})$ that children with autism and typical children could tolerate for discriminating a coarse $\left( \pm 45^{\circ}\right)$ mean signal (high-variability condition). A representation of an example stimulus in which dot directions are drawn from a distribution with $\mathrm{M}=+45^{\circ}$ and $S D=20^{\circ}$ is shown (inset). $D$, Mean proportion of coherent dots $\left( \pm 95 \% \mathrm{Cl}\right.$ ) moving $\pm 90^{\circ}$ required for accurate direction discrimination. A representation of an example stimulus is provided (inset) in which $40 \%$ of the dots move coherently $+90^{\circ}$ and the remainder move in random directions. The signal dots are highlighted in red here, but all dots were white in the task.

vation, children were told that they were competing against cartoon characters. Each "game" contained three "levels": (1) a combined demonstration and criterion phase, (2) a practice phase, and (3) a threshold estimation phase. In all levels in both tasks, direction (left or right of vertical) was randomized on each trial. Children marked their progress throughout the session with a record card and a stamp.

Demonstration and criterion phase. Participants were presented with an animated introduction to the game on the computer. The experimenter then explained each task to participants within the context of four demonstration trials. Next, participants were presented with up to 20 criterion trials. In the direction integration task, no-variability stimuli were presented with a direction $\pm 45^{\circ}$ from vertical. In the motion coherence task, dots moved with $100 \%$ coherence $\pm 90^{\circ}$ from vertical. All participants reached a criterion of four consecutive correct responses within 20 trials. Children responded either verbally or by pointing, with the experimenter relaying the response to the computer. Visual and verbal feedback and encouragement were provided.
Practice phase. Eight practice trials were presented in a fixed order for each task with increasing difficulty. In the direction integration task, four no-variability stimuli and four highvariability stimuli were presented in alternating order. Participants received feedback as before, but there was no criterion for proceeding to the next phase.

Threshold estimation phase. The QUEST adaptive staircase method (Watson and Pelli, 1983) was used to estimate thresholds. In the direction integration task, two staircases (75 trials each) were interleaved for the novariability and high-variability conditions. In the no-variability condition, the QUEST function tracked the basic direction offset threshold ( $84 \%$ correct) in the absence of variability. In the high-variability condition, the mean direction of motion was set to $\pm 45^{\circ}$ and QUEST tracked the maximum level of variability that could be tolerated while correctly discriminating the mean direction $84 \%$ of the time. An additional 15 catch trials were interleaved randomly, presenting stimuli identical to those used in the criterion phase. This yielded a total of 165 trials for each speed condition.

In the motion coherence task, a single QUEST staircase of 75 trials tracked the minimum coherence level required for accurate ( $84 \%$ correct) direction discrimination. As in the direction integration task, there were an additional 15 catch trials that presented stimuli used in the criterion phase. This resulted in 90 trials in total for each speed condition.

Trials were divided into four blocks of equal length for each condition of each task. When the end of a block was reached, participants were given a break where they were shown a simulated graph of the "points" that they and their "opponent" ("Scuba Sam" or the "shark") had attained. These points were randomly jittered around a fixed set of values with the stipulation that participants always received slightly more points than their opponent, which helped to maintain participants' motivation throughout the task (see also Manning et al., 2014).

Fixation analysis. To investigate whether any group differences in motion processing could be attributed to the ability to maintain fixation, we collected fixation data for a subset of 23 children with autism and 22 typical children using a Tobii Technology X2-30 eye tracker. The raw fixation data were $(x, y)$ coordinates sampled during stimulus presentation in each trial of the threshold estimation phase for left and right eye positions relative to the screen's active display area. The data were initially filtered according to a validity code from 0 (signifying the eye was definitely found) to 4 (signifying the eye was not found). All samples with validity codes of 2 or higher were discarded (Tobii Technology Manual, 2013). The $(x, y)$ coordinates were then averaged across the left and right eye for analysis. A measure of fixation stability was derived by pooling the 
SDs of fixation locations in $x$ and $y$ dimensions. The SDs were then log-transformed to minimize the effects of skewness and kurtosis.

Equivalent noise analysis. To supplement the main psychophysical results (Fig. 2), we used equivalent noise analysis to estimate the extent to which local and/or global factors contribute to direction integration in children with autism. Equivalent noise analysis allows two independent limits on direction integration performance to be derived: internal noise, which maps onto the precision with which individual motion directions are estimated, and sampling, which is the effective number of local dot directions that are globally pooled (or averaged). The equivalent noise model describes changes in direction discrimination threshold as a function of directional variability, or external noise (Fig. 1) as follows:

$$
\sigma_{\text {obs }}^{2}=\left[\sigma_{\text {int }}^{2}+\sigma_{\text {ext }}^{2}\right] / n_{\text {samp }}
$$

where $\sigma_{\text {obs }}^{2}$ is the observer's threshold, $\sigma_{\text {int }}^{2}$ is additive internal noise, $\sigma_{\text {ext }}^{2}$ is the external noise added to the stimulus, and $n_{\text {samp }}$ is the effective number of dots used to calculate the mean direction of the stimulus. Equivalent noise analysis typically requires thousands of trials, which is impractical when testing children and clinical groups. However, the novariability and high-variability conditions used here capture two highly informative points on the equivalent noise function with orthogonal confidence intervals that can be used to constrain the fit of the equivalent noise function (Manning et al., 2014; Tibber et al., 2014, 2015). Monte Carlo simulations of a model observer's performance across a range of internal noise and sampling levels showed that sampling $\left(n_{\text {samp }}\right)$ can be estimated by transforming the maximum tolerable level of noise (MTN) in the high-variability condition as follows:

$$
n_{\text {samp }}=\exp \left(0.000121 * \mathrm{MTN}^{2}+0.0357 * \mathrm{MTN}-1.8093\right)
$$

The level of internal noise can then be computed by rearranging Equation 1 and setting external noise to zero $\left(\sigma_{\text {ext }}^{2}=0\right)$ as follows:

$$
\sigma_{\text {int }}^{2}=\sigma_{\text {obs }}^{2} \times n_{\text {samp }}
$$

Note that all noise and sampling estimates quoted are necessarily effective values since we cannot know the observers' underlying strategy for performing the task. For further details of the equivalent noise analysis with children and atypical populations, we refer the reader to Tibber et al. (2014) and Manning et al. (2014).

Data screening and transformation. All participants performed significantly above chance in the catch trials, indicating that they understood the task requirements and were attentive. There was no effect of group on the proportion of incorrect responses to catch trials $\left(F_{(1,64)}=1.74, p=\right.$ $0.19)$ and no interactions between group and speed condition $\left(F_{(1,64)}=\right.$ $0.05, p=0.83)$ or task $\left(F_{(1,64)}=0.07, p=0.79\right)$, so responses to catch trials were not included in the main analysis. One child with autism obtained a motion coherence threshold above one in the slow condition, indicating an inability to perform the task, and was therefore removed from the motion coherence analysis.

All threshold measures and internal noise and sampling estimates were log-transformed to minimize the effects of skewness and kurtosis and then screened for potential outliers, defined as data points lying $> \pm 3$ SDs from the group mean threshold for each speed condition. Three outliers were identified: one belonging to a child with autism in the fast no-variability condition, one belonging to a typical child in the slow high-variability condition, and one corresponding to the sampling estimate from a typical child in the fast condition. Removing these outliers did not change the pattern of the results, so we retained these points to maintain statistical power but replaced the outlying scores with values corresponding to \pm 2.5 SDs from the group mean (Tabachnick and Fidell, 2007).

\section{Results}

Discrimination thresholds

Figure 2, $B-D$, shows mean thresholds for children with autism and typical children in the no-variability and high-variability conditions of the direction integration task and the motion co-

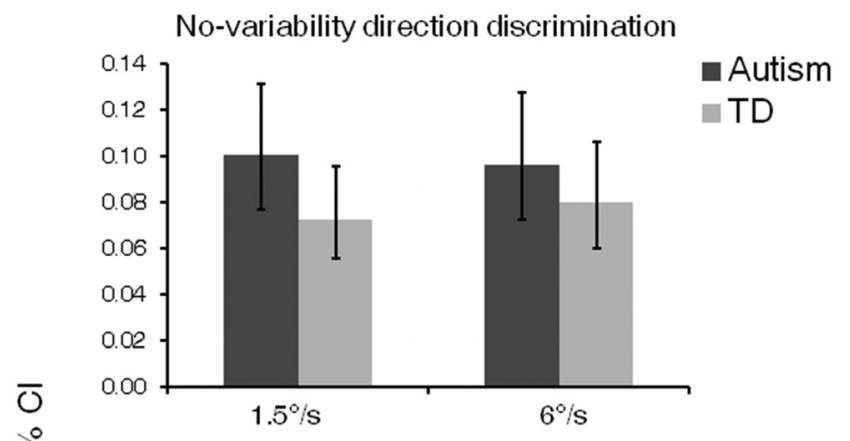

High-variability direction discrimination

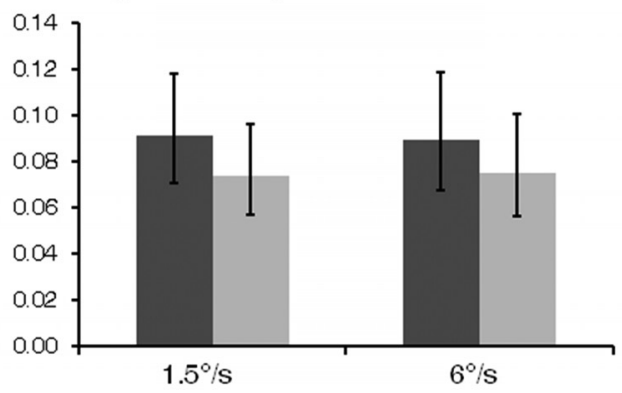

\section{Motion coherence}

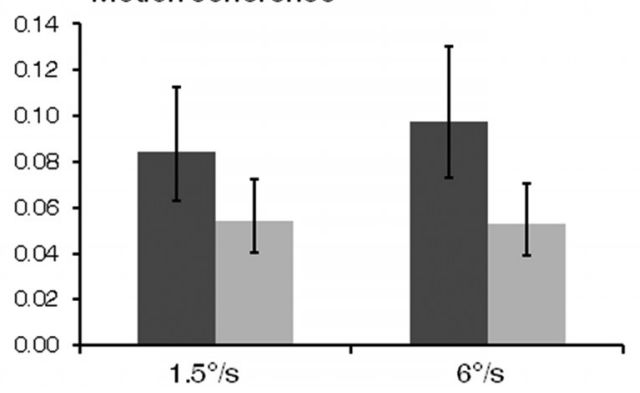

Figure 3. Fixation SDs. Fixation SDs during stimulus presentation in the no-variability (top) and high-variability (middle) conditions of the direction integration task and the motion coherence task (bottom), in which higher values reflect less stable fixations. There was a main effect of task $\left(F_{(2,42)}=4.96, p=0.01, \eta_{p}^{2}=0.19\right)$, with significantly lower fixation SDs in the motion coherence task than in either condition of the direction integration task ( $p s \leq 0.01$ ). There was no overall difference in fixation SDs between the children with autism and typically developing (TD) children $\left(F_{(1,43)}=3.68, p=0.06\right)$, but there was a significant interaction between task and group $\left(F_{(2,42)}=3.88, p=0.03, \eta_{p}^{2}\right.$ $=0.16)$. Post hoc analysis revealed that the groups differed only in the motion coherence task $\left(F_{(1,43)}=7.82, p=0.008, \eta_{p}^{2}=0.15\right)$. The main effect of speed and all other interactions were not significant ( $p s \geq 0.44$ ).

Table 2. Correlations between fixation SD and threshold performance in slow $(1.5 \%)$ and fast $\left(6^{\circ} / 5\right)$ speed conditions

\begin{tabular}{lll}
\hline Threshold measure & & \\
\hline $\begin{array}{l}\text { Direction discrimination } \\
\text { in the absence } \\
\text { of variability }\end{array}$ & $\begin{array}{l}\text { Maximum level of } \\
\text { directional variability } \\
\text { tolerated }\end{array}$ & $\begin{array}{l}\text { Motion } \\
\text { coherence threshold }\end{array}$
\end{tabular}

\begin{tabular}{clll}
\hline Children with autism $(n=23)$ & & \\
$1.5^{\circ} / \mathrm{s}$ & $R=0.22, p=0.31^{a}$ & $R=-0.22, p=0.31^{a}$ & $R=0.15, p=0.52^{b}$ \\
$6^{\circ} / \mathrm{s}$ & $R=0.16, p=0.48^{a}$ & $R=-0.21, p=0.33^{a}$ & $R=0.14, p=0.54^{b}$ \\
Typical children $(n=22)$ & & \\
$1.5^{\circ} / \mathrm{s}$ & $R=0.20, p=0.38^{b}$ & $R=0.25, p=0.26^{b}$ & $R=0.20, p=0.38^{b}$ \\
$6^{\circ} / \mathrm{s}$ & $R=0.16, p=0.49^{b}$ & $R=-0.16, p=0.49^{b}$ & $R=0.04, p=0.86^{b}$
\end{tabular}

${ }^{a}$ Degrees of freedom $=21$.

${ }^{b}$ Degrees of freedom $=20$. 

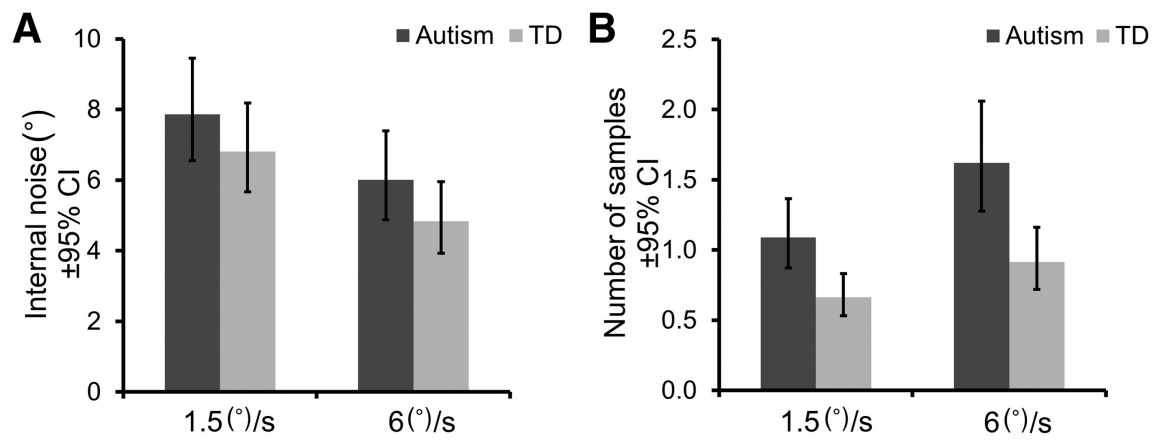

Figure 4. Results of equivalent noise analysis. Mean levels of internal noise $(\boldsymbol{A})$ and the effective number of samples averaged ( $\pm 95 \%$ Cl) $(\boldsymbol{B})$ for children with autism and typically developing (TD) children under the equivalent noise framework.

$\left(F_{(1,64)}=20.18, p<0.001, \eta_{\mathrm{p}}^{2}=0.24\right)$ and lower levels of sampling $\left(F_{(1,64)}=18.18\right.$, $\left.p<0.001, \eta_{\mathrm{p}}^{2}=0.22\right)$ were found in the slow condition than in the fast condition. Our results further show that, under the assumptions of equivalent noise analysis, children with autism effectively sample over more local motion signals than typical children $\left(F_{(1,64)}=14.37, p<0.001, \eta_{\mathrm{p}}^{2}\right.$ $=0.18$; Fig. $4 B)$, but have typical levels of internal noise $\left(F_{(1,64)}=2.23, p=0.14\right.$; Fig. 4A). Critically, increased sampling should lead to reduced thresholds at all levels of variability, which is inconsistent with our finding that children with autism perform comparably to typical children in

herence task. Mixed-design ANOVAs were conducted on these thresholds with speed condition as a within-participants factor and group as a between-participants factor. Consistent with previous research (Ellemberg et al., 2004; Narasimhan and Giaschi, 2012; Manning et al., 2013), we found that children were generally more sensitive to direction information for fast stimuli $(6 \% \mathrm{~s})$ than slow stimuli $(1.5 \%$ s) for all three thresholds (no-variability condition: $F_{(1,64)}=104.15, p<0.001, \eta_{\mathrm{p}}^{2}=0.62$, Fig. $2 B$; highvariability condition: $F_{(1,64)}=18.99, p<0.001, \eta_{\mathrm{p}}^{2}=0.23$, Fig. $2 C$; motion coherence: $F_{(1,63)}=68.05, p<0.001, \eta_{\mathrm{p}}^{2}=0.52$, Fig. $2 D)$. In the absence of stimulus variability, children with autism were as precise at judging dot direction as typical children $\left(F_{(1,64)}=0.69\right.$, $p=0.41$; Fig. $2 B)$ and this was not dependent on speed condition $\left(F_{(1,64)}=0.03, p=0.86\right)$. However, children with autism could tolerate significantly more directional variability when making a coarse direction discrimination than typical children $\left(F_{(1,64)}=\right.$ 17.26, $p<0.001, \eta_{\mathrm{p}}^{2}=0.21$; Fig. $2 C$ ). The effect of group did not interact with the speed condition $\left(F_{(1,64)}=0.73, p=0.40\right)$. In addition, the groups did not differ in their motion coherence thresholds $\left(F_{(1,63)}=0.24, p=0.63\right.$; Fig. $\left.2 D\right)$ and this did not depend on speed condition $\left(F_{(1,63)}=0.05, p=0.83\right)$.

\section{Fixation analysis}

Next, we investigated whether group differences in motion processing could be attributed to differences in the ability to maintain fixation. A mixed-design ANOVA was conducted on fixation SDs with task condition and speed condition as withinparticipants factors, and group as a between-participants factor. Overall, there was no difference in fixation SDs between children with autism and typical children $\left(F_{(1,43)}=3.68, p=0.06\right)$. There was, however, a group by task interaction $\left(F_{(2,42)}=3.88, p=\right.$ $\left.0.03, \eta_{\mathrm{p}}^{2}=0.16\right)$. The SDs of fixation locations for children with autism were significantly greater than for typical children (i.e., reduced fixation stability) in the motion coherence task $\left(F_{(1,43)}=\right.$ 7.82, $\left.p=0.008, \eta_{\mathrm{p}}^{2}=0.15\right)$, but not in the no-variability and high-variability conditions ( $p s \geq 0.16$; Fig. 3 ). Nevertheless, there was no relationship between children's fixation stability and any threshold measure in either group ( $p s \geq 0.26$; Table 2 ).

\section{Equivalent noise analysis}

Finally, the no-variability and high-variability thresholds were modeled with an equivalent noise approach in an attempt to determine whether local and/or global processing limits direction integration performance in our groups (Fig. 1). ANOVAs were conducted on internal noise and sampling estimates, with speed condition as a within-participants factor and group as a betweenparticipants factor. Overall, higher levels of internal noise the no-variability condition (Fig. $2 B$ ). We consider possible reasons for this discrepancy in the Discussion section.

\section{Discussion}

We asked children with autism and age- and ability-matched typical children to judge the mean direction of dots in the presence and absence of directional variability alongside a standard motion coherence task. Children with autism were just as sensitive to direction information as typical children when there was no stimulus variability and showed comparable motion coherence thresholds. Our most unexpected result, however, was that children with autism could tolerate significantly more variability than typical children when judging the mean direction of dots. Our results provide the first evidence of superior direction integration in autism. Our findings allow us to hone in and inform future research on the mechanisms underlying motion perception in autism, by revealing specific enhancements in averaging processes (e.g., those in MT/V5) rather than in low-level visual areas (e.g., those in V1).

Interestingly, the fact that increased integration of direction information failed to go hand-in-hand with increased sensitivity to coherent motion information in autism further highlights that motion coherence thresholds are not a pure measure of integration. In the direction integration tasks, all dots are "signal" dots and therefore the optimal strategy is to average as many dots as possible. In the motion coherence task, however, signal dots are interspersed with "noise" dots and, arguably, an optimal strategy is to segregate the signal dots from noise dots to perform the task. It is therefore possible that children with autism do not show the expected benefits of their increased integration ability because they are less able, or less inclined, to use segregation strategies compared with typical children. Indeed, the competing demands of integration and segregation have been recognized previously (Braddick, 1993; Watamaniuk et al., 2003) and have been proposed to involve distinct neural mechanisms (McDonald et al., 2014). Reduced segregation could result from weaker feedback connections from higher-order areas (Raudies and Neumann, 2010).

Although inconsistent with previous conceptualizations of local and global processing in autism (Frith and Happé, 1994; Mottron et al., 2006), our finding of increased integration is potentially consistent with electrophysiological evidence of larger extrastriate population receptive fields in those with autism (Schwarzkopf et al., 2014). A pattern of increased integration and reduced segregation could potentially be understood within a Bayesian framework because children with autism may not use accumulated knowledge about what is relevant and irrelevant in 
the world to filter out certain information as a consequence of attenuated priors (Pellicano and Burr, 2012). Our results also fit with a cognitive account of increased perceptual capacity in autism (Remington et al., 2009, 2012). This account can explain enhanced performance in visual tasks while also explaining greater distractibility due to increased processing of distracters in individuals with autism. Noise dots, which could be conceptualized as distracters, may be processed more extensively by children with autism than typical children, which may explain why children with autism do not benefit from an increased perceptual capacity in the motion coherence task.

Our results complement two existing studies reporting enhanced motion processing in autism. Chen et al. (2012) reported enhanced speed discrimination specifically when stimuli were separated by a long interstimulus interval and Foss-Feig et al. (2013) reported that individuals with autism required shorter stimulus durations than typical individuals to accurately report the direction of briefly presented high-contrast gratings. Although ours is the first study to demonstrate explicitly enhanced motion integration in individuals with autism, it is notable that the tasks of Chen et al. (2012) and Foss-Feig et al. (2013) similarly required no segregation of signal from noise. It is possible therefore that segregation of signal from noise is a limiting factor for individuals with autism across a range of motion processing tasks.

Our findings of comparable motion coherence thresholds in children with autism and typical children contradict previous findings of elevated motion coherence thresholds in autism (Milne et al., 2002; Pellicano et al., 2005; Manning et al., 2013). Indeed, not all studies have shown elevated motion coherence thresholds in individuals with autism, with many studies showing no differences between groups (Del Viva et al., 2006; Jones et al., 2011). Such discrepant results may arise from a range of differences in participant characteristics and stimulus parameters. For example, elevated motion coherence thresholds have previously been reported for specific stimulus durations (Davis et al., 2006; Robertson et al., 2012, 2014), viewing conditions (Ronconi et al., 2012), and stimulus speeds (Manning et al., 2013). Furthermore, it is possible that elevated motion coherence thresholds are not consistently found in individuals with autism because increased integration and reduced segregation abilities may in some cases cancel each other out.

A secondary aim of our study was to quantify the extent to which internal noise and/or global sampling limits direction integration performance in children with and without autism using the equivalent noise framework. Our results suggest that children with autism have typical levels of internal noise, but can sample over more dots to make their judgments than typical children. Increased sampling should confer an advantage at all levels of directional variability (Dakin et al., 2005). However, in this study, children with autism performed similarly to typical children in the no-variability condition, which limits the conclusions that can be drawn from the equivalent noise analysis. Here, we used a method of equivalent noise analysis that has been adapted successfully for use with children and clinical groups (Manning et al., 2014; Tibber et al., 2014, 2015). Although further insight may be gained from sampling additional points along the equivalent noise function, we note the challenges of presenting lengthy testing sessions to children with and without autism. Nevertheless, the analysis reported here highlights possible interpretations of our results, which should inform future research into the mechanisms underlying enhanced direction integration in children with autism.
It is possible that children with autism might not use the same averaging strategy in the no-variability condition that leads to benefits in the high-variability condition (Allard and Cavanagh, 2012). A similar pattern of equivalent noise function, with specific enhancements at high but not low levels of external noise, has been demonstrated using other related paradigms ( $\mathrm{Lu}$ and Dosher, 1998; Dosher and Lu, 2000). For example, attention can facilitate orientation discrimination performance in the presence of irrelevant contrast noise by allowing the observer to effectively exclude external noise and focus their perceptual analysis on the orientation signal (termed perceptual template retuning; Lu and Dosher, 1998; Dosher and Lu, 2000). However, unlike in previous work, here, we imposed external noise on the relevant stimulus dimension (i.e., direction), so there is no noise to exclude as such. However, it is possible that a similar mechanism of perceptual template retuning may explain why the thresholds of children with autism are less influenced by external noise. In this paradigm, optimal performance constitutes averaging all information. Children with autism may be able to focus on informative characteristics of the stimulus more effectively (and thus more optimally) compared with typical children, who may be integrating over an inappropriately narrow range of directions.

Another possibility is that group differences arise from differences in feature-tracking strategies (Cavanagh, 1992; Lu and Sperling, 1996, 2001) given that both of our stimulus speeds fall within the limit for attentive tracking (Verstraten et al., 2000). A feature-tracking strategy would potentially be detrimental under conditions of high directional variability. If children with autism rely to a lesser extent on such a strategy, then they may show enhanced performance specifically in the presence of directional variability. This account remains speculative, however, and requires validation with stimuli specifically designed to probe the third-order or attentional motion system.

In sum, there is extensive evidence showing that individuals with autism process motion information differently from typical individuals (for review, see Simmons et al., 2009). To date, this has widely been attributed to reduced integration of motion information (Frith and Happé, 1994; Pellicano et al., 2005; Annaz et al., 2010; Robertson et al., 2012; Manning et al., 2013). Our results challenge this common assumption and reveal that children with autism in fact show enhanced integration of direction information. The relatively large sample size and the rigorous psychophysical methods warrant confidence in our results. The reliance on motion coherence paradigms has only served to obscure our understanding of visual processing in autism (and other developmental conditions; Sperling et al., 2006). Atypical motion processing could have serious effects on the everyday lives of individuals with autism. Enhanced integration of motion information might well confer advantages in certain circumstances, but could also pose significant challenges. Indeed, increased pooling of motion information, perhaps in combination with-or as a result of - fewer internal constraints on perception (Pellicano and Burr, 2012), might be one cause of the oftenreported "sensory overload" in those with autism (Kirby et al., 2015).

\section{References}

Adams RJ, Courage ML (2002) Using a Fsingle test to measure human contrast sensitivity from early childhood to maturity. Vision Res 42:12051210. CrossRef Medline

Allard R, Cavanagh P (2012) Different processing strategies underlie voluntary averaging in low and high noise. J Vis 12:6. CrossRef Medline

Annaz D, Remington A, Milne E, Coleman M, Campbell R, Thomas MS, 
Swettenham J (2010) Development of motion processing in children with autism. Dev Sci 13:826-838. CrossRef Medline

Annaz D, Campbell R, Coleman M, Milne E, Swettenham J (2012) Young children with autism spectrum disorder do not preferentially attend to biological motion. J Autism Dev Disord 42:401-408. CrossRef Medline

Barlow H, Tripathy SP (1997) Correspondence noise and signal pooling in the detection of coherent visual motion. J Neurosci 17:7954-7966. Medline

Bertone A, Mottron L, Jelenic P, Faubert J (2003) Motion perception in autism: a "complex" issue. J Cogn Neurosci 15:218-225. CrossRef Medline

Blake R, Turner LM, Smoski MJ, Pozdol SL, Stone WL (2003) Visual recognition of biological motion is impaired in children with autism. Psychol Sci 14:151-157. CrossRef Medline

Braddick O (1993) Segmentation versus integration in visual motion processing. Trends Neurosci 16:263-268. CrossRef Medline

Bradley A, Freeman RD (1982) Contrast sensitivity in children. Vision Res 22:953-959. CrossRef Medline

Brainard DH (1997) The Psychophysics Toolbox. Spatial Vision 10:433436. CrossRef Medline

Cavanagh P (1992) Attention-based motion perception. Science 257:15631565. CrossRef Medline

Chen Y, Norton DJ, McBain R, Gold J, Frazier JA, Coyle JT (2012) Enhanced local processing of dynamic visual information in autism: evidence from speed discrimination. Neuropsychologia 50:733-739. CrossRef Medline

Dakin S, Frith U (2005) Vagaries of visual perception in autism. Neuron 48:497-507. CrossRef Medline

Dakin SC, Mareschal I, Bex PJ (2005) Local and global limitations on direction integration assessed using equivalent noise analysis. Vision Res 45: 3027-3049. CrossRef Medline

Davis G, Plaisted-Grant K (2015) Low endogenous neural noise in autism. Autism 19:351-362. CrossRef Medline

Davis RA, Bockbrader MA, Murphy RR, Hetrick WP, O’Donnell BF (2006) Subjective perceptual distortions and visual dysfunction in children with autism. J Autism Dev Disord 36:199-210. CrossRef Medline

Del Viva MM, Igliozzi R, Tancredi R, Brizzolara D (2006) Spatial and motion integration in children with autism. Vision Res 46:1242-1252. CrossRef Medline

Dosher BA, Lu ZL (2000) Noise exclusion in spatial attention. Psychol Sci 11:139-146. CrossRef Medline

Ellemberg D, Lewis TL, Dirks M, Maurer D, Ledgeway T, Guillemot JP, Lepore F (2004) Putting order into the development of sensitivity to global motion. Vision Res 44:2403-2411. CrossRef Medline

Foss-Feig JH, Tadin D, Schauder KB, Cascio CJ (2013) A substantial and unexpected enhancement of motion perception in autism. J Neurosci 33:8243-8249. CrossRef Medline

Frith U, Happé F (1994) Autism: beyond "theory of mind". Cognition 50: 115-132. CrossRef Medline

Gotham K, Risi S, Pickles A, Lord C (2007) The Autism Diagnostic Observation Schedule: revised algorithms for improved diagnostic validity. J Autism Dev Disord 37:613-627. CrossRef Medline

Gotham K, Risi S, Dawson G, Tager-Flusberg H, Joseph R, Carter A, Hepburn S, McMahon W, Rodier P, Hyman SL, Sigman M, Rogers S, Landa R, Spence MA, Osann K, Flodman P, Volkmar F, Hollander E, Buxbaum J, Pickles A, Lord C (2008) A replication of the Autism Diagnostic Observation Schedule (ADOS) revised algorithms. J Am Acad Child Adolesc Psychiatry 47:642-651. CrossRef Medline

Hubel DH, Wiesel TN (1962) Receptive fields, binocular interaction and functional architecture in the cat's visual cortex. J Physiol 160:106-154. CrossRef Medline

Jones CR, Swettenham J, Charman T, Marsden AJ, Tregay J, Baird G, Simonoff E, Happé F (2011) No evidence for a fundamental visual motion processing deficit in adolescents with autism spectrum disorders. Autism Res 4:347-357. CrossRef Medline

Kirby AV, Dickie VA, Baranek GT (2015) Sensory experiences of children with autism spectrum disorder: in their own words. Autism 19:316-326. CrossRef Medline

Kleiner M, Brainard DH, Pelli DG (2007) What's new in Psychtoolbox-3? Perception 36.

Lord C, Rutter M, DiLavore PC, Risi S (1999) Autism Diagnostic Observation Schedule. Los Angeles: Western Psychological Services.
Lord C, Rutter M, DiLavore P, Risi S, Gotham K, Bishop SL (2012) Autism Diagnostic Observation Schedule (ADOS-2). Torrance, CA: Western Psychological Services.

Lu ZL, Dosher BA (1998) External noise distinguishes attention mechanisms. Vision Res 38:1183-1198. CrossRef Medline

Lu ZL, Sperling G (1996) Three systems for visual motion perception. Curr Dir Psychol Sci 5:44-53. CrossRef

Lu ZL, Sperling G (2001) Three-systems theory of human visual motion perception: review and update. J Opt Soc Am A 18:2331-2370. CrossRef

Manning C, Charman T, Pellicano E (2013) Processing slow and fast motion in children with autism spectrum conditions. Autism Res 6:531-541. CrossRef Medline

Manning C, Dakin SC, Tibber MS, Pellicano E (2014) Averaging, not internal noise, limits the development of coherent motion processing. Dev Cogn Neurosci 10:44-56. CrossRef Medline

McDonald JS, Clifford CWG, Solomon SS, Chen SC, Solomon SG (2014) Integration and segregation of multiple motion signals by neurons in area MT of primate. J Neurophys 111:369-378. CrossRef Medline

Milne E, Swettenham J, Hansen P, Campbell R, Jeffries H, Plaisted K (2002) High motion coherence thresholds in children with autism. J Child Psychol Psychiatry 43:255-263. CrossRef Medline

Mottron L, Dawson M, Soulières I, Hubert B, Burack J (2006) Enhanced perceptual functioning in autism: an update, and eight principles of autistic perception. J Autism Dev Disord 36:27-43. CrossRef Medline

Narasimhan S, Giaschi D (2012) The effect of dot speed and density on the development of global motion perception. Vision Res 62:102-107. CrossRef Medline

Newsome WT, Paré EB (1988) A selective impairment of motion perception following lesions of the middle temporal visual area (MT). J Neurosci 8:2201-2211. Medline

Newsome WT, Wurtz RH, Dürsteler MR, Mikami A (1985) Deficits in visual motion processing following ibotenic acid lesions of the middle temporal visual area of the macaque monkey. J Neurosci 5:825-840. Medline

Pelli DG (1997) The VideoToolbox software for visual psychophysics: transforming numbers into movies. Spatial Vision 10:437-442. CrossRef Medline

Pellicano E, Burr D (2012) When the world becomes 'too real': a Bayesian explanation of autistic perception. Trends Cogn Sci 16:504-510. CrossRef Medline

Pellicano E, Gibson L, Maybery M, Durkin K, Badcock DR (2005) Abnormal global processing along the dorsal visual pathway in autism: a possible mechanism for weak visuospatial coherence? Neuropsychologia 43: 1044-1053. CrossRef Medline

Raudies F, Neumann H (2010) A neural model of the temporal dynamics of figure-ground segregation in motion perception. Neural Netw 23:160 176. CrossRef Medline

Remington AM, Swettenham JG, Lavie N (2012) Lightening the load: perceptual load impairs visual detection in typical adults but not in autism. J Abnorm Psychol 121:544-551. CrossRef Medline

Remington A, Swettenham J, Campbell R, Coleman M (2009) Selective attention and perceptual load in autism spectrum disorder. Psychol Sci 20:1388-1393. CrossRef Medline

Robertson CE, Martin A, Baker CI, Baron-Cohen S (2012) Atypical integration of motion signals in autism spectrum conditions. PLoS One 7:e48173. CrossRef Medline

Robertson CE, Thomas C, Kravitz DJ, Wallace GL, Baron-Cohen S, Martin A, Baker CI (2014) Global motion perception deficits in autism are reflected as early as primary visual cortex. Brain 137:2588-2599. CrossRef Medline

Ronconi L, Gori S, Ruffino M, Franceschini S, Urbani B, Molteni M, Facoett A (2012) Decreased coherent motion discrimination in autism spectrum disorder: the role of attentional zoom-out deficit. PLoS One 7:e49019. CrossRef Medline

Rutter M, Bailey A, Lord C (2003) Social Communication Questionnaire. Los Angeles: Western Psychological Services.

Schwarzkopf DS, Anderson EJ, de Haas B, White SJ, Rees G (2014) Larger extrastriate population receptive fields in autism spectrum disorders. J Neurosci 34:2713-2724. CrossRef Medline 
Simmons DR, Robertson AE, McKay LS, Toal E, McAleer P, Pollick FE (2009) Vision in autism spectrum disorders. Vision Res 49:2705-2739. CrossRef Medline

Sperling AJ, Lu ZL, Manis FR, Seidenberg MS (2006) Motion-perception deficits and reading impairment: it's the noise, not the motion. Psychol Sci 17:1047-1053. CrossRef Medline

Tabachnick BG, Fidell LS (2007) Using multivariate statistics, Ed 5. Boston: Allyn and Bacon.

Tibber MS, Kelly MG, Jansari A, Dakin SC, Shepherd AJ (2014) An inability to exclude visual noise in migraine. Invest Ophthalmol Vis Sci 55:25392546. CrossRef Medline

Tibber MS, Anderson EJ, Bobin T, Carlin P, Shergill SS, Dakin SC (2015) Local and global limits on visual processing in schizophrenia. PloS One 10:e0117951. CrossRef Medline
Verstraten FA, Cavanagh P, Labianca AT (2000) Limits of attentive tracking reveal temporal properties of attention. Vision Res 40:3651-3664. CrossRef Medline

Watamaniuk SN, Flinn J, Stohr RE (2003) Segregation from direction differences in dynamic random-dot stimuli. Vision Res 43:171-180. CrossRef Medline

Watson AB, Pelli DG (1983) QUEST: A Bayesian adaptive psychometric method. Percept Psychophys 33:113-120. CrossRef Medline

Wechsler D (1999) Wechsler abbreviated scale of intelligence. San Antonio, TX: Psychological Corporation.

Wechsler D (2011) WASI-II: Wechsler abbreviated scale of intelligence, Ed 2. San Antonio, Texas: Psychological Corporation.

World Health Organisation (1993) The ICD-10 classification of mental and behavioural disorders: diagnostic criteria for research. Geneva: World Health Organization. 